\title{
Application of the Systems Approach to the Management of Complex Water Systems
}

\author{
Slobodan P. Simonovic ${ }^{(D)}$ \\ Department of Civil and Environmental Engineering, The University of Western Ontario, \\ London, ON N6A 3K7, Canada; simonovic@uwo.ca
}

Received: 13 October 2020; Accepted: 16 October 2020; Published: 19 October 2020

\begin{abstract}
This paper provides an introduction to, and an overview of, the Special Issue on the application of systems approach to the management of complex water systems. The main motivation in proposing this Special Issue was that today, more than ever, we need a systems approach to assist in dealing with the difficulties introduced by the increase in the complexity of water resource problems, consideration of environmental impacts, and the introduction of the principles of sustainability. This issue offers an opportunity to review applications of the systems approach to water resource management and draw lessons from worldwide experience relevant to future water problems. The Special Issue includes 15 contributions that offer an interesting view into contemporary problems, approaches, and issues related to management of complex water resources systems. It will be presumptuous to say that these 15 contributions characterize the success or failure of the systems approach to support water resources decision-making. However, these contributions offer some interesting lessons from the current experience and trace possible future work directions.
\end{abstract}

Keywords: systems; complexity; water resources; management

\section{Introduction}

During the past five decades, we have witnessed a tremendous evolution in water resource systems management. From the early days and the introduction of the approach by [1] and some of the most significant texts [2-4] up to today's practice, it is very clear that the approach matured and became essential to support water resources decision making. Three of the characteristics of this evolution should be noted in particular: (1) the application of the systems approach to complex water management problems has been established as one of the most important advances in the field of water resource management; (2) the past five decades have brought a remarkable transformation of attitude in the water resource management community towards environmental concerns, and action to address these concerns; and (3) applying the principles of sustainability to water resource decision-making requires major changes in the objectives on which decisions are based, and an understanding of the complicated inter-relationships between existing ecological, economic and social factors.

Today, more than ever, we need appropriate tools that can assist in dealing with the challenges introduced by the increase in the complexity of water resource problems, consideration of environmental impacts, and the introduction of principles of sustainability. The systems approach is one such tool. This Special Issue offers an opportunity to review some applications of the systems approach to water resource management and draw lessons from worldwide experience relevant to the solution of future water problems.

Let me repeat the basic definition of a system here. Simonovic [4] defines "a system as a collection of various structural and non-structural elements that are connected and organized in such a way as to achieve some specific objective through the control and distribution of material resources, energy, and information". The systems approach is characterized by emergence (the whole is different than 
the sum of its parts), self-organization (cooperation, interdependence and competition yield stabilizing homeostasis), nonlinearity (small changes in part of the system can have excessively significant effects across the whole), and feedback loops (the outputs of the system affect its inputs).

The experience presented through contributions of the Special Issue and [5] offer the following summary of the current state of the water resources systems approach: (i) the water resources systems approach today offers a scientific interdisciplinary context for dealing with the complex practical issues of water management and prediction of the water resources future; (ii) the systems approach is helping all those who are responsible for water resources management to organize water related information and improve the decision-making; (iii) the implementation of the systems approach allows us to address complex problems in close collaboration with the general public; (iv) the systems approach, allows through clear articulation of assumptions, use of models, identification of feedback relationships, and monitoring system behavior, and helps decision-makers better anticipate future conditions and make smarter management decisions; (v) the tools of systems analysis (simulation, optimization and multi-objective analysis) provide decision-makers with the information for full understanding of the dynamics that direct the interactions between the social (people and economy), natural (water, land and air) and constructed systems (buildings, roads, bridges etc.); (vi) the systems approach is contributing to the improvement in human behavior by using systems thinking; and (vii) the systems approach leads to greater practical and safer uncertainty management policies for increasing the resilience of water systems to changing conditions.

In the review presented in this Special Issue [5,6] it is pointed out that "a success reached today must contribute to further evolution of the water resources systems approach to successfully address the serious water challenges faced by society. The future activities must continue: to deal with the most difficult complex water problems; to conduct further practice-based as well as fundamental research; and provide further capacity building".

\section{Contributions}

The Special Issue includes 15 contributions that offer an interesting view into contemporary problems, approaches, and issues related to the management of complex water resources systems. It is not easy to classify the contributions published in the Special Issue. Their order of presentation in the Issue reflects my understanding of the contributions.

\section{The Special Issue Organization of Contributions}

The Issue opens with the paper by Prof. D.P. Loucks [7], who is one of the leaders in this field and has provided invaluable contributions that influenced academia, industry, and governments. His message focuses on the transition in the water resources systems approach from preoccupation with methodological issues to implementation experiences and innovation. Prof. Loucks sends a message that a crisis in water is no longer an abstraction for many. Adapting to globally changing conditions is the challenge for all of us.

The following papers by Morley and Savic [8], and Rusforth et al. [9], deal with water scarcity. Morley and Savic offer an optimization approach to the "Lower Thames Control Diagram", a set of control curves subject to a large number of constraints. The diagram is used to regulate abstraction of water for the public drinking water supply for London, UK, and to maintain downstream environmental and navigational flows. The optimized configuration of the Lower Thames Control Diagram was adopted by the water utility and the environmental regulators and is currently in use. Rusforth et al. present a rigorous quantitative, systems-based model to measure a municipality's water portfolio security using multiple objectives. This simple model can be operationalized using readily available data to capture water security dimensions that go far beyond typical reliability and cost analysis. They used the Phoenix Metropolitan Area as a case study.

Horriche and Benabdallah [10], Lee and Kang [11], and Hattab et al. [12] further the discussion to the applications of groundwater management, multipurpose reservoir operations, and urban drainage, 
respectively. The first paper examines the impact of an artificial recharge site on groundwater level and salinity using treated domestic wastewater for the Korba aquifer (north eastern Tunisia). Groundwater flow and solute transport models are utilized in the identification of suitable areas for aquifer recharge. Lee and Kang, in their study, clarify relationships within the social and hydrological systems and quantitatively analyze the effects of a multi-purpose dam on the target society using a system dynamics simulation approach. Hattab et al. implement the soft system engineering and Analytic Network Process (ANP) approaches in a methodological framework to improve the understanding of the stakeholders within the sustainable urban drainage system and their key priorities, which leads to selecting the appropriate modeling technique according to the end-use application.

The three contributions by Rehana et al. [13], Agrawal et al. [14], and Sabbaghian and Nejadhashemi [15] bring uncertainty into the discussion of complex water resources systems management. Rehana et al. appraise the quantification of uncertainties in systems modeling in India and discuss various water resource management and operation models. The basic formulation of models for probabilistic, fuzzy, and grey/inexact simulation, optimization, and multi-objective analyses to water resource design, planning, and operations are very well presented in this work. Agrawal et al. present a study that includes identifying and quantifying the gap between people's perception of exposure and susceptibility to the risk, a lack of coping capacity and objective assessment of risk and resilience, as well as estimating an integrated measure of disaster resilience in a community. The proposed method has been applied to floods in the hope that the study will encourage a broader debate if a unified strategy for disaster resilience would be feasible and beneficial in Canada. Sabbaghian and Nejadhashemi present a risk-based consensus-based group decision-support system model for choosing the desirable urban water strategy. This model is successfully implemented for the Kashafroud urban watershed in Iran, for selecting the more desirable urban water strategy in 2040.

Stojkovic and Simonovic [16], Hooshyar et al. [17], and Aivazidou and Tsolakis [18] address various issues in managing complex water problems. Stojkovic and Simonovic study the impact of climate change on the management of a complex multipurpose water system and present a set of steps of the climate change impact analysis process. They used the Lim water system in Serbia (southeast Europe) as a case study. Furthermore, their study analyzed the uncertainty in the system outputs introduced by different steps of the modeling process. Hooshyar et al. deal with reservoir operations optimization under uncertainty. They introduce reinforcement learning, a simulation-based stochastic optimization approach that can effectively eliminate the curse of modeling that arises from the need to calculate a very large transition probability matrix. This paper presents a multi-agent approach combined with an aggregation/decomposition method. The method has been applied to a real-world five-reservoir problem, the Parambikulam-Aliyar Project in India. Aivazidou and Tsolakis present an interesting and unusual problem of wine-water footprint assessment to investigate the water dynamics of wine production in Italy and the wine sector's water efficiency. This research provides insights for practitioners in the Italian wine sector to develop water-friendly corporate schemes for enhancing the added value of their products.

The next two papers by Madani and Shafiee-Jood [19] and Ponnambalam and Mousavi [20] target a controversial development related to socio-hydrology as a "new science" of interaction between human and natural systems. Madani and Shafiee-Jood correctly point that the socio-hydrology studies show strong overlap with what has already been in the literature, especially in the water resources systems and coupled human and natural systems (CHANS) areas. Nevertheless, the work in these areas has been generally dismissed by the socio-hydrology literature. Their paper overviews some of the general concerns about originality, practicality, and contributions of socio-hydrology. It is argued that, while in theory, a common-sense approach about the need for considering humans as an integral component of water resources systems models can strengthen our coupled human-water systems research, the current approaches, and trends in socio-hydrology can make this interest area less inclusive and interdisciplinary. Ponnambalam and Mousavi state that coupled human-natural system models provide the practical approach needed for applications both in the descriptive science of 
socio-hydrology and in the prescriptive method of integrated water resources management. Since the introduction of socio-hydrology as a "new science" various responses and criticisms clearly indicating no novelty in the concept and presence of interaction between human activities and water systems in the literature over a number of decades. However, in this paper there are some issues like (i) treatment of integrated water resources management (IWRM) as a tool, not a process; (ii) a view of socio-hydrology as science and IWRM as an engineering approach (which is clearly wrong); (iii) stating that socio-hydrology promotes CHANS (the literature of socio-hydrology, unfortunately, had not originally admitted CHANS); and (iv) proposing CHANS as a modeling tool (which is problematic as CHANS is not a tool but an analysis approach/framework which takes advantage of many tools including system dynamics, economics, and others).

The Special Issue ends with my paper [6] that states that systems approaches based on simulation, optimization, and multi-objective analyses, in deterministic, stochastic, and fuzzy forms, have demonstrated great success in supporting effective water resources management in the last half of last century. In this paper, I explore the future opportunities that will utilize advancements in systems theory that might transform the management of water resources on a broader scale. The paper presents performance-based water resources engineering as a methodological framework to extend the systems approach's role in improved sustainable water resources management under changing conditions (with special consideration given to rapid climate destabilization).

\section{Conclusions}

The key messages we can extract from the submissions included in this Special Issue are quite broad and definitively not limited to what has been addressed with these contributions. It can be concluded that the water resources systems approach: (i) offers a very reachable portfolio of applications and a scientific interdisciplinary context for dealing with the complex practical issues of water management and prediction of the water resources future; (ii) is helping all those who are responsible for water resources management to organize water related information in order to distinguish between the noise and important information and improve the decision-making; (iii) provides the information necessary to understand resource flows and the larger water resources management context in close collaboration with the general public to understand the relationships between human behavior and environmental and economic impacts of water resources management decisions; (iv) is helping the improvement of planning and forecasting by articulation of assumptions, use of models, identification of feedback relationships, and monitoring system behavior; (v) offers the tools (simulation, optimization and multi-objective analysis) that are helping to improve the quality of decision-making; (vi) is contributing to the improvement in human behavior by using systems thinking; and (vii) leads to greater practical and safer risk management policies.

There are still remaining challenges necessary to respond to global changes that affect and alter the hydrologic cycle, and that define human relationships with natural systems. It is our hope that some of the ideas addressed in this collection of papers will help all of us in become more innovative, and increase our collaboration in securing solutions for a sustainable future.

Funding: This research received no external funding.

Acknowledgments: My time for working on this Special Issue was supported by the Discovery Grant from the Natural Sciences and Engineering Research Council of Canada. I would like to express my gratitude to all reviewers of the submissions included in the Special Issue, WATER Journal editors, and staff for their effort, time, and significant contributions to this publication.

Conflicts of Interest: The author declares no conflict of interest. 


\section{References}

1. Maass, A.; Hufschmidt, M.; Dorfman, R.; Thomas, H.; Marglin, S.; Fair, G. Design of Water-Resource Systems: New Techniques for Relating Economic Objectives, Engineering Analysis, and Governmental Planning; Harvard Univ. Press: Cambridge, MA, USA, 1962.

2. Loucks, D.P.; Stedinger, J.R.; Haith, D.A. Water Resources Systems Planning and Analysis; Prentice Hall: Englewood Cliffs, NJ, USA, 1981.

3. Loucks, D.P.; van Beek, E. Water Resources Systems Planning and Management: An Introduction to Methods, Models and Applications; UNESCO: Paris, France, 2005; p. 680.

4. Simonovic, S.P. Managing Water Resources: Methods and Tools for a Systems Approach; UNESCO: Paris, France; Earthscan James \& James: London, UK, 2009; p. 576. ISBN 978-1-84407-554-6.

5. Brown, C.M.; Lund, J.R.; Cai, X.; Reed, P.M.; Zagona, E.A.; Ostfeld, A.; Hall, J.; Characklis, G.W.; Yu, W.; Brekke, L. The future of water resources systems analysis: Toward a scientific framework for sustainable water management. Water Resour. Res. 2015, 51, 6110-6124. [CrossRef]

6. Simonovic, S.P. Systems Approach to Management of Water Resources-Toward Performance Based Water Resources Engineering. Water 2020, 12, 1208. [CrossRef]

7. Loucks, D.P. From Analyses to Implementation and Innovation. Water 2020, 12, 974. [CrossRef]

8. Morley, M.; Savić, D. Water Resource Systems Analysis for Water Scarcity Management: The Thames Water Case Study. Water 2020, 12, 1761. [CrossRef]

9. Rushforth, R.R.; Messerschmidt, M.; Ruddell, B.L. A Systems Approach to Municipal Water Portfolio Security: A Case Study of the Phoenix Metropolitan Area. Water 2020, 12, 1663. [CrossRef]

10. Jarraya Horriche, F.; Benabdallah, S. Assessing Aquifer Water Level and Salinity for a Managed Artificial Recharge Site Using Reclaimed Water. Water 2020, 12, 341. [CrossRef]

11. Lee, S.; Kang, D. Analyzing the Effectiveness of a Multi-Purpose Dam Using a System Dynamics Model. Water 2020, 12, 1062. [CrossRef]

12. El Hattab, M.H.; Theodoropoulos, G.; Rong, X.; Mijic, A. Applying the Systems Approach to Decompose the SuDS Decision-Making Process for Appropriate Hydrologic Model Selection. Water 2020, 12, 632. [CrossRef]

13. Rehana, S.; Rajulapati, C.R.; Ghosh, S.; Karmakar, S.; Mujumdar, P. Uncertainty Quantification in Water Resource Systems Modeling: Case Studies from India. Water 2020, 12, 1793. [CrossRef]

14. Agrawal, N.; Elliott, M.; Simonovic, S.P. Risk and Resilience: A Case of Perception versus Reality in Flood Management. Water 2020, 12, 1254. [CrossRef]

15. Javidi Sabbaghian, R.; Nejadhashemi, A.P. Developing a Risk-Based Consensus-Based Decision-Support System Model for Selection of the Desirable Urban Water Strategy: Kashafroud Watershed Study. Water 2020, 12, 1305. [CrossRef]

16. Stojkovic, M.; Simonovic, S.P. System Dynamics Approach for Assessing the Behaviour of the Lim Reservoir System (Serbia) under Changing Climate Conditions. Water 2019, 11, 1620. [CrossRef]

17. Hooshyar, M.; Mousavi, S.J.; Mahootchi, M.; Ponnambalam, K. Aggregation-Decomposition-Based Multi-Agent Reinforcement Learning for Multi-Reservoir Operations Optimization. Water 2020, 12, 2688. [CrossRef]

18. Aivazidou, E.; Tsolakis, N. A Water Footprint Review of Italian Wine: Drivers, Barriers, and Practices for Sustainable Stewardship. Water 2020, 12, 369. [CrossRef]

19. Madani, K.; Shafiee-Jood, M. Socio-Hydrology: A New Understanding to Unite or a New Science to Divide? Water 2020, 12, 1941. [CrossRef]

20. Ponnambalam, K.; Mousavi, S.J. CHNS Modeling for Study and Management of Human-Water Interactions at Multiple Scales. Water 2020, 12, 1699. [CrossRef]

Publisher's Note: MDPI stays neutral with regard to jurisdictional claims in published maps and institutional affiliations. 